\title{
Stimulation of Low-Temperature Dissolution of Organic Matter of Brown Coal, Composition of Bitumoids
}

\author{
Sergey Zherebtsov*, Kirill Shpakodraev, Natalia Malyshenko, \\ Konstantin Votolin, Zinfer Ismagilov \\ Federal Research Center of Coal and Coal Chemistry, Siberian Branch, Russian Academy of Sciences, \\ Kemerovo, 650000 Russia. \\ *Corresponding author. E-mail: sizh@yandex.ru
}

\begin{abstract}
The paper presents data on the yield, chemical composition of bitumen extracted from the brown coal of the Tyulgan deposit. Bitumens were extracted from brown coal by the following methods: I) sequential extraction with ethanol, n-heptane, alcohol-benzene according to the Grefe method, II) low-temperature dissolution of the organic mass of coal (OMC) by alkylation and subsequent extraction of bitumoids; III) stimulation of alkylation by ultrasound and subsequent extraction of bitumoids. It is shown that the use of ultrasonic exposure during the O-alkylation process has a positive effect on the yield of bitumoids - the yield increased to $52 \%$. The obtained samples were studied using the methods of IR spectroscopy, ${ }^{13} \mathrm{C}$ NMR (CPMAS), gas chromatography-mass spectrometry (GC-MS). A number of individual compounds were identified in the composition of bitumen and bitumoids during the study by the GCMS method: gamma-tocopherol, Stigmast-4-en-3-one, betaHydroxyallobetulan, 1-Hexadecanol, Oleyl alcohol, etc. Among the identified compounds, various biologically active substances are present.
\end{abstract}

Keywords: Bitumen, Brown coal, Extraction, O-alkylation, Ultrasonic action, Biologically active substances

\section{INTRODUCTION}

Brown coals are usually burned to generate heat and electricity, while the colossal chemical potential that is concentrated in them is irretrievably lost. Coal chemistry processing is one of the most significant methods in the complex use of brown coal. The most promising method is extraction using various methods of stimulating low-temperature dissolution of organic matter of brown coal. This makes it possible to extract the numbers of valuable products from brown coal: humic substances and bitumen (mountain wax) [1,2].
Bitumen is a valuable product in high demand on the world market, the cost of which in its "raw" form reaches $3000 €$ per ton. When processing bitumen, it is customary to distinguish two components, wax and resin. Wax in its structure and characteristics of use is very similar to natural plant essential waxes and is used in cosmetics, for the manufacture of protective and polishing compositions, precision casting, et al. In addition, terpenoids, hopanes, sterols, and some vitamins, and other biologically active substances (BAS) characteristic of vegetation, were found in waxes and resins. Therefore, special attention is attracted by studies aimed at studying the possibility of extracting biologically active substances in pure form or in the form of narrow fractions, which can 
find their application in cosmetics, medicine, agriculture [1-5].

This work is devoted to the study of the group and component composition of fractions of brown coal bitumen, as well as ways to increase the yield of bitumen during their extraction, such as $\mathrm{O}$-alkylation and O-alkylation under the influence of ultrasound.

\section{EXPERIMENTAL}

To study the group and component composition of bitumen, several experiments were carried out, during which bitumen was extracted from coal with successive extraction according to Grefe method (I), from O-alkylated coal (II), and O-alkylated coal under the influence of ultrasound (III).

Brown coal (1B) (Table 1) of the Tyulgan deposit of the South Ural Basin (TBC) was used as a raw material for the extraction of bitumen.

\subsection{The Grefe Extraction}

The Grefe extraction was carried out with the sequential use of solvents: ethanol, n-heptane, ethanol-benzene 1:1 [4]. As a result of the process carried out, 3 fractions were obtained: I R1, I W, I R2. The volume of each of the solvents used was $100 \mathrm{~mL}$, the duration of extraction with each of the solvents was $3 \mathrm{~h}$, the total yield of extraction bitumen was $16.0 \%$ (Table 2). The results of the proximate and ultimate analysis of de-bituminated coal (CR1) are presented in Table 1.

\subsection{O-Alkylating Treatment and Extraction of Bitumoids}

O-alkylating treatment and extraction of bitumoids were carried out under conditions calculated for the maximum yield of bitumoids [6]. Process parameters: $5 \mathrm{~g}$ of coal; $69.75 \mathrm{~mL}$ of $\mathrm{n}$ butanol, n-heptane $100 \mathrm{~mL}, 9.8 \%$ of the volume of the OPA solution $\left(\mathrm{w}=79.9 \%, \rho=1.626 \mathrm{~g} / \mathrm{cm}^{3}\right)$, the duration of the alkylation process is $6.0 \mathrm{~h}$. The resulting bitumoids were separated into wax (II W) and resin (II R) fractions using a methodology based on the dissolution of resins in acetone $[2,7,8]$.

After the completion of the process, residual resins were extracted from the remaining coal mass with alcohol-benzene (1:1), according to the Grefe method. As a result, the total yield of bitumoids was $44.4 \%$ (Table 2). The results of the proximate and ultimate analysis of the obtained de-bituminated coal (CR2) are shown in Table 1.
Table 1. Results of the proximate and ultimate analysis of initial and de-bituminated coals

\begin{tabular}{|l|l|l|l|l|l|l|l|}
\hline Sample & $\mathbf{W}^{\mathrm{a}}$ & $\mathbf{A}^{\mathbf{d}}$ & $\mathbf{V}^{\text {daf }}$ & $\mathbf{C}^{\text {daf }}$ & $\mathbf{H}^{\text {daf }}$ & $\begin{array}{l}\mathbf{H} / \mathbf{C} \\
\text { at }\end{array}$ & $\begin{array}{l}(\mathbf{O + N + S})^{\text {daf }} \mathbf{b y} \\
\text { difference }\end{array}$ \\
\hline TBC & 9.1 & 21.5 & 65.9 & 57.3 & 6.3 & 1.3 & 36.4 \\
\hline CR1 & 7.5 & 27.0 & 64.4 & 63.6 & 5.9 & 1.1 & 30.5 \\
\hline CR2 & 3.1 & 37.5 & 64.1 & 65.9 & 5.0 & 0.9 & 29.1 \\
\hline CR3 & 1.9 & 39.3 & 63.8 & 67.8 & 4.5 & 0.8 & 27.7 \\
\hline
\end{tabular}

Note. ${ }^{\text {daf }}$ - dry ash-free state of the sample; $\mathrm{W}^{\mathrm{a}}$ - analytical moisture in accordance with GOST R 52917-2008; $\mathrm{A}^{\mathrm{d}}$ - ash content on a dry sample in accordance with GOST 11022-95; $\mathrm{V}^{\text {daf }}$ - content of volatile substances according to GOST 6382-2001. Measurement error-no more than $2 \%$.

\subsection{O-Alkylation Treatment and Extraction of Bitumoids During the Intensification of the Process by Ultrasound}

O-alkylation treatment and extraction of bitumoids during the intensification of the process by ultrasound were carried out with the following process parameters: associated solvent - n-heptane, $100 \mathrm{~mL}$; alkylating alcohol - n-butanol, $50 \mathrm{~mL}$; the catalyst of the process is OPA ( $w=79.9 \%, \rho=1.626$ $\left.\mathrm{g} / \mathrm{cm}^{3}\right), 5 \%$ by volume of the mixture; brown coal -5 $\mathrm{g}$; the duration of the process is $0.5 \mathrm{~h}$; the process was carried out at the boiling point of the mixture $\left(98 \pm 5^{\circ} \mathrm{C}\right)$. Ultrasound was generated by an UZDN-2T unit, frequency $22 \mathrm{kHz}$. After the completion of the process, residual resins were extracted from the remaining coal mass with alcohol-benzene (1:1), according to the Grefe method The bitumoids yield under these conditions was $52.0 \%$ Table 2 .

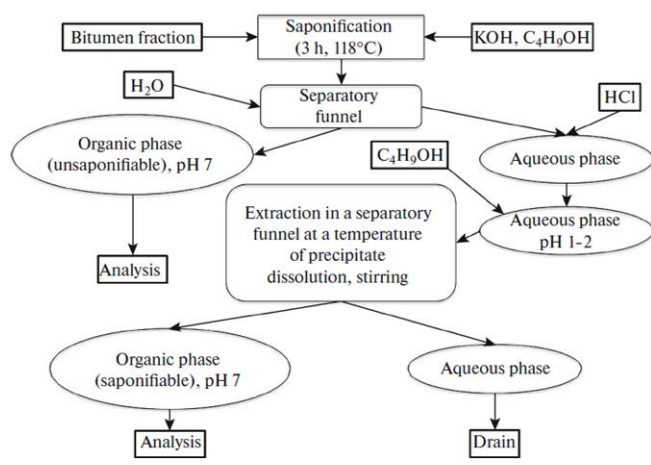

Figure 1. Schematic diagram of separation into saponifiable and unsaponifiable components

The obtained bitumoids were subsequently fractionated into wax (III W) and resin (III R) [2, 7, 8]. The results of the proximate and ultimate analysis of the obtained de-bituminated coal (CR3) are shown in Table 1. All the obtained samples for additional fractionation were divided into saponifiable and 
unsaponifiable components [4, 9]. The separation Figure 1 was carried out using a saponification reaction (butanol, $\mathrm{KOH}$ to $\mathrm{pH}=11-12$, process temperature $118^{\circ} \mathrm{C}$, duration $3 \mathrm{~h}$ ).

Table 2. Bitumen yield during extraction according to Grefe method (I)

\begin{tabular}{|c|c|c|c|c|c|c|}
\hline \multirow[t]{2}{*}{ Fraction } & \multirow[t]{2}{*}{$\mathbf{E}^{\text {daf }}, \%$} & \multirow{2}{*}{$\mathbf{E}_{\text {total }}{ }^{\text {daf }}, \%$} & \multicolumn{4}{|c|}{$\begin{array}{l}\text { Results of separation into saponifiable and } \\
\text { unsaponifiable components }\end{array}$} \\
\hline & & & sap., \% & unsap., \% & losses, \% & total, \% \\
\hline \multicolumn{7}{|c|}{ Grefe sequential extraction (I) } \\
\hline I R1 (resin extracted with ethanol) & 12.2 & \multirow{3}{*}{16.0} & 34.7 & 61.9 & 3.4 & 100 \\
\hline I W (wax extracted with n-heptane) & 1.2 & & 18.1 & 80.3 & 1.6 & 100 \\
\hline $\begin{array}{l}\text { I R2 (resin extracted with alcohol- } \\
\text { benzene) }\end{array}$ & 2.6 & & 49.3 & 49.5 & 1.2 & 100 \\
\hline \multicolumn{7}{|l|}{ Alkylating process with $n$-butanol (II) } \\
\hline II W (wax) & 16.5 & \multirow{2}{*}{44.4} & 72.5 & 25.4 & 2.1 & 100 \\
\hline II R (resin) & 27.9 & & 76.8 & 17.3 & 5.9 & 100 \\
\hline \multicolumn{7}{|c|}{ Alkylating process with $n$-butanol under the influence of ultrasound (III) } \\
\hline III W (wax) & 23.2 & \multirow{2}{*}{52.0} & 68.6 & 28.5 & 2.9 & 100 \\
\hline III R (resin) & 28.8 & & 85.9 & 10.2 & 3.9 & 100 \\
\hline
\end{tabular}

For narrower fractionation, the obtained fractions were separated using the method of liquid column chromatography (LC) $[9,10]$. Glass columns with the following parameters: diameter $-10 \mathrm{~mm}$; length - 500 $\mathrm{mm}$. Silica gel, GOST 3956-76, was used as a filler, the grain size of silica gel was $0.2-0.5 \mathrm{~mm}$. Following the recommendations [11] and to avoid overloading the column, the loading of the sample for separation was $0.06 \mathrm{~g}$. Solvents were sequentially used as eluents: toluene, ethyl acetate, butanol, ethanol, ethanol-formic acid (1:1). The residual fraction was recovered with hot butanol $\left(\mathrm{t}=118^{\circ} \mathrm{C}\right)$. The yield of fractions was monitored using a refractometer according to the refractive index of the eluent used.

The samples obtained were studied using IR spectroscopy, ${ }^{13} \mathrm{C}$-NMR (CPMAS) spectroscopy, chromatography-mass spectrometry (GC-MS).

The IR spectra were recorded on an Infralum-FT 801 FTIR spectrophotometer at a resolution of $4 \mathrm{~cm}^{-1}$ with the accumulation of 16 scans in a range of $4000-500 \mathrm{~cm}^{-1}$ in dry $\mathrm{KBr}$.

High-resolution solid-state NMR spectra were recorded on a Bruker Avance III-300 instrument at 75 $\mathrm{MHz}$ using standard methodology cross-polarization with rotation at a magical angle (CP/MAS) and the accumulation of 1024 scans at room temperature. Chemical shifts are reported relative to tetramethylsilane (TMS).

The GC-MS analysis was carried out on an Agilent $6890 \mathrm{~N}$ chromatograph instrument with an Agilent 5973 mass-selective detector under the following conditions: HP-5ms capillary column, injector temperature, $290^{\circ} \mathrm{C}$; solvent removal, $4 \mathrm{~min}$; split ratio, 50:1, helium carrier gas flow rate, 1 $\mathrm{mL} / \mathrm{min}$, injected sample volume, $5.0 \mu \mathrm{L}$, and column temperature programming from $50^{\circ} \mathrm{C}$ after a $3 \mathrm{~min}$ exposure to $280^{\circ} \mathrm{C}$ at a rate of $5^{\circ} \mathrm{C} / \mathrm{min}$ and holding at $280^{\circ} \mathrm{C}$ for $60 \mathrm{~min}$. The concentrations of individual compounds were measured on a total ion current basis. The components of the test samples were identified using the NIST-11 and Wiley libraries of spectra.

\section{RESULTS AND DISCUSSION}

The data obtained Tables 2 show that the Oalkylation process allowed a significant increase in the yield of bitumoids, up to $44.4 \%$, which is $28.4 \%$ more than in the case of sequential extraction according to Grefe. Intensification of the alkylation process by ultrasound made it possible to increase the bitumoids yield - the yield of $52.0 \%$, with a process duration of $0.5 \mathrm{~h}$. When separating the test samples, as a result of the saponification reaction, the proportion of saponifiable substances changes as follows Tables 2: successive extraction according to Graefe $<\mathrm{O}$-alkylation<O-alkylation under ultrasonic action.

IR spectra of the studied samples are shown in Figure 2. The assignment of absorption bands was carried out on the basis of literature sources [12-15]. The samples under study have an identical group composition and are complex multicomponent mixtures (substances). The absorption bands in the region of $3400-3200 \mathrm{~cm}^{-1}$ are stretching vibrations of 
the -OH group of alcohols and phenols linked by hydrogen bonds. The absorption bands in the region of $3000-2800 \mathrm{~cm}^{-1}$ are stretching vibrations of $-\mathrm{CH}_{2}$ and $-\mathrm{CH}_{3}$ groups. In the region of $1750-1690 \mathrm{~cm}^{-1}$ there are absorption bands characteristic of stretching vibrations of $>\mathrm{C}=\mathrm{O}$ saturated aliphatic acids and $\alpha$ halogen-substituted aliphatic acids, esters of longchain carboxylic acids. In the range of 1475-1450 $\mathrm{cm}^{-1}$, the spectra of the samples contain absorption bands characteristic of bending vibrations of $-\mathrm{CH}_{2}$ groups. Absorption bands in the range of 1175-1125 $\mathrm{cm}^{-1}$ are characteristic of plane bending vibrations of 1-, 1,3-, 1,2,3-, 1,3,5-aromatic compounds. The absorption bands in the $730-710 \mathrm{~cm}^{-1}$ region are related to the pendulum vibrations of the methylene groups of long alkane chains.

Analyzing the ${ }^{13} \mathrm{C}-\mathrm{NMR}$ (CPMAS) data, compounds with long alkane chains predominate in the studied samples, mainly related to esters, carboxylic acids, and alcohols. Aromatic compounds are present in small amounts Table 3. The assignment of signals was carried out based on the literature sources [12-14]. Peaks in the range of 5-48 ppm indicate the presence of straight alkane chains and alkyl groups. Peaks in the range of 48-90 ppm indicate the presence of substances in the alcohol group. In the region of 90-108 ppm, the peaks were indicating the presence of acetal groups. Peaks in the region of 108-145 ppm are characteristic of the aromatic group of substances. The presence of peaks in the range of 145-165 ppm is typical for substances with an aromatic ring having a hydroxyl group. Substances with a carboxyl group are presented in the spectrum in peaks in the range of 165-187 ppm. Peaks in the $187-220 \mathrm{ppm}$ region indicate the presence of substances with a carbonyl group.
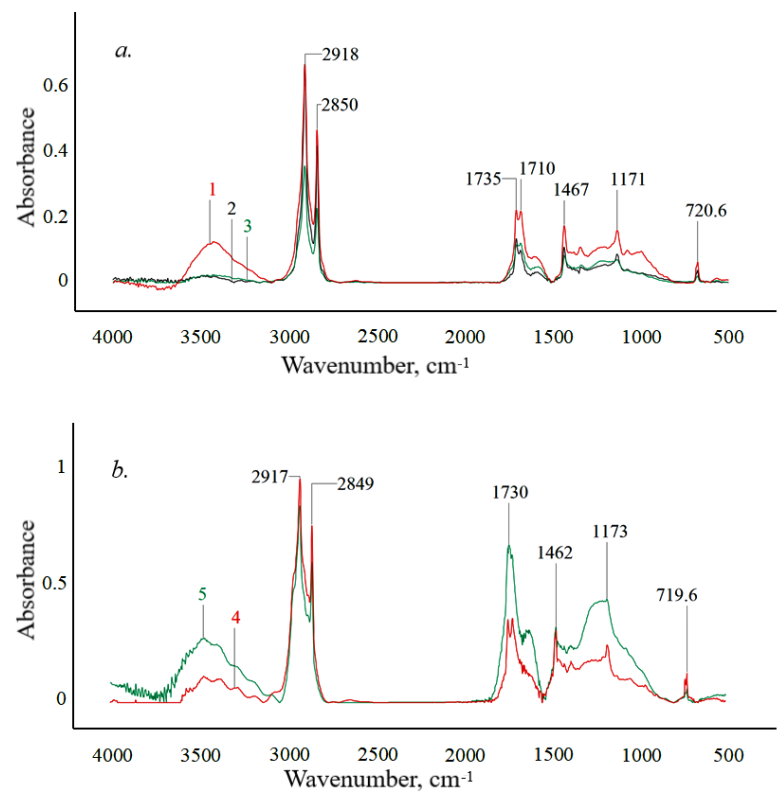

Figure 2. $a$. - IR-spectra of ethanol (1), n-heptane (2), alcohol-benzene (3) bitumen fractions (I); $b$. - IR spectra of bitumoids (II) from O-alkylated brown coal (4), bitumoids (III) from O-alkylated brown coal with the intensification of the process by ultrasound (5)

Table 3. Integral intensities (\%) of spectral regions in the ${ }^{13} \mathrm{C}-\mathrm{NMR}$ spectra (CP MAS) of the samples under study

\begin{tabular}{|c|c|c|c|c|c|c|c|c|c|c|}
\hline \multirow[t]{2}{*}{ Sample } & \multirow{2}{*}{$\begin{array}{l}220-187 \\
C=O\end{array}$} & \multirow{2}{*}{$\begin{array}{l}\text { 187-165 } \\
\text { COOH }\end{array}$} & \multirow{2}{*}{$\begin{array}{l}165-145 \\
C_{a r-o}\end{array}$} & \multirow{2}{*}{$\begin{array}{l}145-108 \\
C_{a r}\end{array}$} & \multirow{2}{*}{$\begin{array}{l}108-90 \\
C_{\text {O-Alk-O }}\end{array}$} & \multirow{2}{*}{$\begin{array}{l}90-48 \\
C_{\text {alk-o }}\end{array}$} & \multirow{2}{*}{$\begin{array}{l}48-5 \\
C_{\text {alk }}\end{array}$} & \multicolumn{3}{|c|}{$\begin{array}{l}\text { Structural-group } \\
\text { parameters }\end{array}$} \\
\hline & & & & & & & & $f_{a r}$ & $f_{a l}$ & $f_{\text {ar/al }}$ \\
\hline \multicolumn{11}{|c|}{ Grefe sequential extraction (I) } \\
\hline I R1 & 2.3 & 2.9 & \begin{tabular}{|l|}
1.9 \\
\end{tabular} & 6.9 & 2.6 & 11.6 & 71.0 & 8.8 & 85.2 & 0.10 \\
\hline I R1S & 2.9 & 3.9 & 2.7 & 9.1 & 2.7 & 13.8 & 64.2 & 11.8 & 80.7 & 0.14 \\
\hline I R1U & 1.6 & 1.8 & 1.3 & 4.8 & 2.2 & 9.8 & 78.0 & 6.1 & 90.0 & 0.06 \\
\hline I W & 1.5 & 2.2 & 1.3 & 4.3 & 2.5 & 8.1 & 79.9 & 5.6 & 90.5 & 0.06 \\
\hline I WS & 1.7 & 2.6 & 1.7 & 5.1 & 2.6 & 7.9 & 77.8 & 6.8 & 88.3 & 0.07 \\
\hline I WU & 1.4 & 2.3 & 1.1 & 3.7 & 2.1 & 8.0 & 81.3 & 4.8 & 91.3 & 0.05 \\
\hline I R2 & 3.0 & 3.6 & 2.7 & 8.7 & 3.1 & 12.8 & 64.6 & 11.4 & 80.4 & 0.14 \\
\hline I R2S & 3.1 & 4.2 & 3.0 & 10.3 & 2.9 & 13.5 & 62.2 & 13.3 & 78.6 & 0.17 \\
\hline I R2U & 1.3 & 1.7 & 1.1 & 4.1 & 2.2 & 8.7 & 79.8 & 5.2 & 90.7 & 0.05 \\
\hline \multicolumn{11}{|c|}{ Alkylating process with $n$-butanol (II) } \\
\hline Alkyl. & 1.6 & 2.1 & 1.4 & 4.9 & 2.1 & 8.2 & 78.5 & 6.3 & 88.8 & 0.07 \\
\hline
\end{tabular}




\begin{tabular}{|l|l|l|l|l|l|l|l|l|l|l|}
\hline bitumoids & & & & & & & & & & \\
\hline II W & 2.3 & 2.1 & 1.6 & 5.9 & 2.3 & 9.6 & 74.9 & 7.5 & 86.8 & 0.09 \\
\hline II WS & 1.2 & 2.4 & 1.3 & 4.1 & 2.4 & 8.2 & 79.9 & 5.4 & 90.5 & 0.06 \\
\hline II WU & 2.3 & 1.4 & 1.8 & 7.9 & 2.2 & 12.4 & 71.2 & 9.7 & 85.8 & 0.11 \\
\hline II R & 5.2 & 6.1 & 5.0 & 16.0 & 4.2 & 17.9 & 41.0 & 20.9 & 63.1 & 0.33 \\
\hline II RS & 5.0 & 7.1 & 5.8 & 17.6 & 4.1 & 17.8 & 40.8 & 23.4 & 62.7 & 0.37 \\
\hline II RU & 2.7 & 2.3 & 2.0 & 8.2 & 2.2 & 15.2 & 66.0 & 10.3 & 83.4 & 0.12 \\
\hline Alkylating process with $n$-butanol under the influence of ultrasound (III) & & & & & & \\
\hline $\begin{array}{l}\text { Alkyl. under } \\
\text { the infl. of } \\
\text { ultrasound } \\
\text { bitumoids }\end{array}$ & 3.1 & 4.0 & 2.9 & 9.2 & 3.2 & 13.8 & 61.8 & 12.2 & 78.8 & 0.15 \\
\hline III W & 1.9 & 2.8 & 1.8 & 5.6 & 2.8 & 10.5 & 72.9 & 7.4 & 86.2 & 0.09 \\
\hline III WS & 1.4 & 3.0 & 1.6 & 5.0 & 2.5 & 8.5 & 77.2 & 6.6 & 88.2 & 0.07 \\
\hline III WU & 1.2 & 1.6 & 1.2 & 4.8 & 2.2 & 9.2 & 79.3 & 6.0 & 90.7 & 0.06 \\
\hline III R & 6.5 & 7.3 & 7.8 & 23.6 & 4.7 & 16.3 & 31.1 & 31.4 & 52.2 & 0.60 \\
\hline III RS & 5.6 & 7.4 & 6.7 & 20.5 & 4.4 & 17.4 & 35.8 & 27.2 & 57.6 & 0.47 \\
\hline III RU & 1.6 & 2.4 & 1.8 & 7.3 & 2.1 & 11.2 & 73.1 & 9.1 & 86.4 & 0.10 \\
\hline
\end{tabular}

Note: I R1 ethanol-extracted resin; I R1S saponifiable component of the resin extracted with ethanol; I R1U unsaponifiable component of the resin extracted with ethanol; I W wax, extracted with n-heptane; I WS saponifiable component of wax extracted with $n$-heptane; I WU unsaponifiable component of wax extracted with $n$-heptane; I R2 resin extracted with alcohol-benzene; I R2S saponifiable component of the resin extracted with alcohol-benzene; I R2U unsaponifiable component of the resin extracted with alcohol-benzene; II W wax fraction of bitumoids; II WS saponifiable component of the bitumoids wax fraction; II WU unsaponifiable component of the wax fraction of bitumoids; II R resin fraction of bitumoids; II RS saponifiable component of the resin fraction of bitumoids; II RU unsaponifiable component of the resin fraction of bitumoids; III W wax fraction of bitumoids extracted from O-alkylated under the influence of ultrasound brown coal; III WS saponifiable component of the wax fraction of bitumoids extracted from brown coal alkylated under the influence of ultrasound; III WU unsaponifiable component of the wax fraction of bitumoids extracted from brown coal alkylated under the influence of ultrasound; III R resin fraction of bitumoids extracted from O-alkylated brown coal under the influence of ultrasound; III RS saponifiable component of the resin fraction of bitumoids extracted from alkylated under the influence of ultrasound brown coal; III RU unsaponifiable component of the resin fraction of bitumoids extracted from brown coal alkylated under the influence of ultrasound.

According to Table 3, for all the samples under study, the structural-group parameters [16] were calculated $\mathrm{f}_{\mathrm{ar}}$ - the aromaticity index, $\mathrm{f}_{\mathrm{al}}$ - the aliphatic index and $f_{a r} / f_{a l}$ - the ratio of aromaticity to aliphaticity, where:

$$
\begin{aligned}
& \mathrm{f}_{\mathrm{ar}}=\mathrm{C}_{\mathrm{ar}-\mathrm{O}}+\mathrm{C}_{\mathrm{ar}} ; \\
& \mathrm{f}_{\mathrm{al}}=\mathrm{C}_{\text {O-alk-O }}+\mathrm{C}_{\text {alk-O }}+\mathrm{C}_{\text {alk }} ; \\
& \mathrm{f}_{\mathrm{ar}} / \mathrm{f}_{\mathrm{al}}=\left(\mathrm{C}_{\mathrm{ar}-\mathrm{O}}+\mathrm{C}_{\mathrm{ar}}\right) /\left(\mathrm{C}_{\text {O-alk-O}}+\mathrm{C}_{\text {alk-O }}+\mathrm{C}_{\text {alk }}\right) .
\end{aligned}
$$

Analyzing the calculated structural-group parameters (Table 3), we think that aromatic substances during separation as a result of the saponification reaction are concentrated in the saponifiable components of the studied samples. Comparing the indicators $f_{\text {ar }}$ alkylated bitumoids and alkylated under the influence of ultrasound, in the latter we observed an increase in the indicator by 2 times. At the same time, there is a tendency in the concentration of aromatic substances in the saponifiable components of the resin fraction (II RS, III RS).

In the study of bitumen and their fractions by GCMS, more than 200 individual compounds were identified in their composition, including Oleic acid, Octadecanoic acid, Heneicosane; Heptadecane, Oxirane, hexadecyl-, Podocarpa-5,8,11,13-tetraen-7one, 13-hydroxy-14-isopropyl-, gamma-Tocopherol, Stigmast-4-en-3-one, beta-Hydroxyallobetulane, 1Hexadecanol, Oleyl Alcohol, Octacosanoic acid, Nonacosanoic acid, Nonacosenoic acid, Triacontanoic acid and others. Particular attention is attracted by BAS [17, 18], which are present in the composition of bitumen and bitumoids in significant concentrations, some of them are presented in Table 4. 
Table 4. Biologically active substances identified in the composition of the test samples

\begin{tabular}{|c|c|c|c|}
\hline $\begin{array}{l}\text { Sample, } \\
\text { fraction }\end{array}$ & $\begin{array}{l}\text { Substance } \\
{[17,18]^{*}}\end{array}$ & $\begin{array}{l}\text { Relative } \\
\text { content in the } \\
\text { sample, \% }\end{array}$ & $\begin{array}{l}\text { Match } \\
\text { according to the } \\
\text { NIST11 base, \% }\end{array}$ \\
\hline \multirow{3}{*}{ I R1U } & Ferruginol & 0.66 & 87 \\
\hline & Sugiol & 0.69 & 95 \\
\hline & Betulin & 0.36 & 99 \\
\hline \multirow{3}{*}{ I WS } & Ferruginol & 0.18 & 87 \\
\hline & Octadecanoic acid & 0.6 & 91 \\
\hline & Oleic acid & 1.02 & 99 \\
\hline \multirow{2}{*}{ I R2U } & Sugiol & 0.45 & 99 \\
\hline & n-Tetracosanol-1 & 3.55 & 95 \\
\hline \multirow{2}{*}{ II WS } & n-Tetracosanol-1 & 7.7 & 95 \\
\hline & Octacosanoic acid & 13.2 & 99 \\
\hline \multirow{2}{*}{ II WU } & beta-Amyrin & 0.96 & 99 \\
\hline & Stigmastanol & 2.44 & 99 \\
\hline \multirow{2}{*}{ II RS } & Sugiol & 5.41 & 99 \\
\hline & Heptanedioic acid & 2.3 & 83 \\
\hline \multirow{2}{*}{ II RU } & Sugiol & 7.01 & 99 \\
\hline & Betulin & 4.96 & 99 \\
\hline \multirow{3}{*}{ III WS } & Octacosanoic acid & 21.03 & 91 \\
\hline & Triacontanoic acid & 9.48 & 82 \\
\hline & $\begin{array}{l}\text { 9-Hexadecenoic } \\
\text { acid }\end{array}$ & 2.23 & 70 \\
\hline \multirow{4}{*}{ III RU } & Sugiol & 0.35 & 86 \\
\hline & Octacosanoic acid & 9.08 & 83 \\
\hline & Hexacosanoic acid & 6.29 & 80 \\
\hline & Oleic acid & 16.4 & 90 \\
\hline
\end{tabular}

* - Carboxylic acids are presented as butyl esters
For narrower fractionation and isolation of valuable lipid fractions enriched with BAS, LC separation of samples bitumens and bitumoids was carried out (Table 5).

The LC separation of the samples made it possible to increase the proportion of identified compounds in the GC/MS analysis. From the results obtained, it should be noted that in the fractions eluted with toluene, there is a tendency to extract substances related to alcohols, terpenes, and sterols. Among the substances identified in these fractions, there were biologically active substances such as Sugiol, a plant metabolite with antiviral and antitumor activity, Ferruginol, plant metabolite with antitumor and antibacterial activity, Betulin with analgesic properties, antiviral, anti-inflammatory, and antitumor properties.

Moreover, the elution with ethanol made it possible to extract several fractions with a high relative content of Oleic acid - up to $75.8 \%$ (I R2), which is also a BAS. Several fractions eluted with a mixture of ethanol and formic acid from alkylated samples were not able to be analyzed. In the obtained chromatograms of these fractions, the intensity of the peaks of substances relative to the peaks of the solvent is very low.

Changing the chromatographic parameters during the analysis of these fractions, within the operating limits of the device, did not affect the readings obtained for these fractions on the chromatograms. Probably, the operating temperature of the instrument with this hardware is insufficient for evaporation and separation of fractions obtained by elution with a mixture of ethanol and formic acid during LC separation. 
Table 5. Substances with the highest relative contents in the obtained fractions during LC separation, according to GC-MS data, (relative contents, \%)*

\begin{tabular}{|c|c|c|c|c|c|}
\hline \multirow{2}{*}{\multicolumn{2}{|c|}{ Eluent }} & Substance $* *$ & $\begin{array}{l}\text { Relative content } \\
\text { in the sample, } \%\end{array}$ & Substance $* *$ & $\begin{array}{l}\text { Relative content in } \\
\text { the sample, } \%\end{array}$ \\
\hline & & \multicolumn{2}{|c|}{ I R1 } & \multicolumn{2}{|c|}{ I W } \\
\hline \multirow{11}{*}{ Toluene } & & n-Tetracosanol-1 & 21.4 & 9-Hexadecenoic acid & 10.5 \\
\hline & & 1-Heptacosanol & 9.0 & n-Tetracosanol-1 & 7.7 \\
\hline & & Octadecanoic acid & 7.3 & \multirow{9}{*}{ Behenic alcohol } & \multirow{9}{*}{5.3} \\
\hline & 1 & $\beta$-Sitosterol & 4.4 & & \\
\hline & 1 & $\begin{array}{l}\text { Podocarpa-5,8,11,13- } \\
\text { tetraen-7-one, 13- } \\
\text { hydroxy-14-isopropyl }\end{array}$ & 2.9 & & \\
\hline & & Sugiol & 3.0 & & \\
\hline & \multirow{5}{*}{2} & Tetracosanoic acid & 16.3 & & \\
\hline & & n-Tetracosanol-1 & 16.2 & & \\
\hline & & 1-Heptacosanol & 13.9 & & \\
\hline & & Octacosanoic acid & 12.5 & & \\
\hline & & Hexacosanoic acid & 9.9 & & \\
\hline \multirow{4}{*}{\multicolumn{2}{|c|}{ Ethyl acetate }} & Octacosanoic acid & 16.3 & Hexadecanoic acid & 9.1 \\
\hline & & Hexacosanoic acid & 13.1 & Octadecanoic acid & 3.6 \\
\hline & & Tetracosanoic acid & 12.3 & \multirow{2}{*}{ Oleic acid } & \multirow{2}{*}{3.9} \\
\hline & & Triacontanoic acid & 9.4 & & \\
\hline \multirow{4}{*}{\multicolumn{2}{|c|}{ Butanol }} & Hexacosanoic acid & 17.2 & Hexadecanoic acid & 41.3 \\
\hline & & Oleic acid & 15.4 & \multirow{3}{*}{ 9-Hexadecenoic acid } & \multirow{3}{*}{28.8} \\
\hline & & Tetracosanoic acid & 11.6 & & \\
\hline & & Octacosanoic acid & 10.7 & & \\
\hline \multirow{3}{*}{\multicolumn{2}{|c|}{ Ethanol }} & Oleic acid & 71.9 & Oleic acid & 73.8 \\
\hline & & Hexadecanoic acid & 11.1 & Hexadecanoic acid & 8.8 \\
\hline & & Decanedioic acid & 7.7 & Decanedioic acid & 7.7 \\
\hline \multirow{3}{*}{$\begin{array}{l}\text { Ethanol + } \\
\text { formic acid } \\
(1: 1)\end{array}$} & & Tetracosanoic acid & 12.9 & & \\
\hline & 1 & \multirow{2}{*}{ Hexacosanoic acid } & \multirow{2}{*}{11.1} & Oleic acid & 69.9 \\
\hline & 2 & & & Oleic acid & 16.8 \\
\hline \multirow{3}{*}{\multicolumn{2}{|c|}{$\begin{array}{l}\text { Butanol } \\
\left(\mathbf{t}=\mathbf{1 1 8}^{\circ} \mathrm{C}\right)\end{array}$}} & Octacosanoic acid & 11.6 & Tetradecanoic acid & 6.6 \\
\hline & & Triacontanoic acid & 8.4 & \multirow{2}{*}{ Hexadecanoic acid } & \multirow{2}{*}{6.4} \\
\hline & & 9-Tetradecenoic acid & 7.9 & & \\
\hline \multirow{2}{*}{\multicolumn{2}{|c|}{ Eluent }} & Substance ** & $\begin{array}{l}\text { Relative content } \\
\text { in the sample, \% }\end{array}$ & Substance ** & $\begin{array}{l}\text { Relative content in } \\
\text { the sample, } \%\end{array}$ \\
\hline & & I I & & & \\
\hline \multirow{4}{*}{\multicolumn{2}{|c|}{ Toluene }} & Oleic acid & 8.6 & Tetracosanoic acid & 8.6 \\
\hline & & n-Tetracosanol-1 & 4.2 & Octacosanoic acid & 7.8 \\
\hline & & 1-Нехасосаnol & 34 & Hexacosanoic acid & 6.3 \\
\hline & & 1-Hexacosanol & 3.4 & n-Tetracosanol-1 & 5.5 \\
\hline & & & & Tetracosanoic acid & 11.5 \\
\hline & & & & Hexacosanoic acid & 11.0 \\
\hline Ethyl acetate & & Hexadecanoic acid & 61.9 & Octacosanoic acid & 10.8 \\
\hline & & & & Triacontanoic acid & 6.6 \\
\hline & & Hexadecanoic acid & 33.5 & Tetracosanoic acid & 10.4 \\
\hline & & & & Hexadecanoic acid & 9.2 \\
\hline Butanol & & 9-Hexadecenoic acid & 30.0 & 9-Hexadecenoic acid & 8.5 \\
\hline & & & & Octacosanoic acid & 7.6 \\
\hline Fthangl & & Oleic acid & 758 & Oleic acid & 65.1 \\
\hline Ethanor & & Olelc acid & 15.8 & Hexadecanoic acid & 7.1 \\
\hline & & & & Oleic acid & 28.0 \\
\hline formic acid & 1 & Oleic acid & 50.9 & Decanedioic acid & 10.0 \\
\hline
\end{tabular}




\begin{tabular}{|c|c|c|c|c|}
\hline$(1: 1)$ & Oleic acid & 38.7 & & \\
\hline \multirow{4}{*}{$\begin{array}{l}\text { Butanol } \\
\left(t=118^{\circ} \mathrm{C}\right)\end{array}$} & Oleic acid & 14.9 & Octacosanoic acid & 13.9 \\
\hline & \multirow{3}{*}{ Hexadecanoic acid } & \multirow{3}{*}{10.2} & 9-Hexadecenoic acid & 10.7 \\
\hline & & & Hexacosanoic acid & 10.7 \\
\hline & & & Tetracosanoic acid & 7.9 \\
\hline \multirow[t]{2}{*}{ Eluent } & Substance $* *$ & $\begin{array}{l}\text { Relative content } \\
\text { in the sample, } \%\end{array}$ & Substance $* *$ & $\begin{array}{c}\text { Relative content in } \\
\text { the sample, \% }\end{array}$ \\
\hline & \multicolumn{2}{|l|}{ II R } & \multicolumn{2}{|c|}{ III W } \\
\hline \multirow{5}{*}{ Toluene } & Hexadecanoic acid & 15.0 & Octacosanoic acid & 18.0 \\
\hline & 9-Hexadecenoic acid & 9.3 & Tetracosanoic acid & 14.8 \\
\hline & Pentadecanoic acid & 6.0 & \multirow{3}{*}{ Hexacosanoic acid } & \multirow{3}{*}{14.5} \\
\hline & Tetradecanoic acid & 4.3 & & \\
\hline & Sugiol & 3.0 & & \\
\hline \multirow{3}{*}{ Ethyl acetate } & Hexadecanoic acid & 19.9 & Hexadecanoic acid & 27.4 \\
\hline & Hexadecenoic acid & 15.0 & 9-Hexadecenoic acid & 15.6 \\
\hline & Oleic acid & 12.4 & Oleic acid & 8.7 \\
\hline \multirow{5}{*}{ Butanol } & 9-Hexadecenoic acid & 20.0 & Hexadecanoic acid & 24.7 \\
\hline & Hexadecanoic acid & 17.8 & 9-Hexadecenoic acid & 21.7 \\
\hline & \multirow{3}{*}{ Oleic acid } & \multirow{3}{*}{12.8} & Oleic acid & 10.3 \\
\hline & & & Tetradecanoic acid & 6.9 \\
\hline & & & Pentadecanoic acid & 5.0 \\
\hline \multirow{2}{*}{ Ethanol } & Oleic acid & 54.4 & \multirow{2}{*}{ Oleic acid } & \multirow{2}{*}{72.2} \\
\hline & 9-Hexadecenoic acid & 6.4 & & \\
\hline $\begin{array}{l}\text { Ethanol }+ \\
\text { formic acid } \\
(1: 1)\end{array}$ & 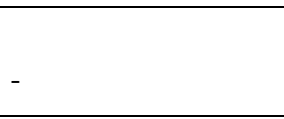 & - & - & - \\
\hline \multirow{3}{*}{$\begin{array}{l}\text { Butanol } \\
\left(t=118^{\circ} \mathrm{C}\right)\end{array}$} & Oleic acid & 18.6 & Octacosanoic acid & 14.2 \\
\hline & \multirow{2}{*}{ Hexadecanoic acid } & \multirow{2}{*}{13.6} & Hexacosanoic acid & 10.0 \\
\hline & & & Hexadecanoic acid & 8.7 \\
\hline \multirow{2}{*}{ Eluent } & \multicolumn{2}{|c|}{ Substance ** } & \multicolumn{2}{|c|}{ Relative content in the sample, $\%$} \\
\hline & \multicolumn{4}{|c|}{ III R } \\
\hline \multirow{3}{*}{ Toluene } & \multicolumn{2}{|l|}{ Hexadecanoic acid } & \multicolumn{2}{|c|}{24.8} \\
\hline & 9-Hexadecenoic acid & & & \\
\hline & Oleic acid & & & \\
\hline Ethyl acetate & Hexadecanoic acid & & & \\
\hline & 9-Hexadecenoic acid & & & \\
\hline Rutonol & Hexadecanoic acid & & & \\
\hline Butanol & Oleic acid & & & \\
\hline & Tetradecanoic acid & & & \\
\hline & 9-Hexadecenoic acid & & & \\
\hline Ethanol & Hexadecanoic acid & & & \\
\hline & Oleic acid & & & \\
\hline $\begin{array}{l}\text { Ethanol + } \\
\text { formic acid } \\
(1: 1)\end{array}$ & - & & & \\
\hline Butanol & Hexadecanoic acid & & & \\
\hline$\left(\mathrm{t}=118^{\circ} \mathrm{C}\right)$ & Octadecanoic acid & & & \\
\hline
\end{tabular}

\section{CONCLUSION}

Thus, the alkylation treatment with $n$-butanol in the presence of catalyst $\mathrm{H}_{3} \mathrm{PO}_{4}$ made it possible to significantly increase the bitumoids yield to $44.4 \%$. The intensification of the process by ultrasonic action made it possible to reduce the duration of the process to $0.5 \mathrm{~h}$ and increase the bitumoids yield to $52.0 \%$, which is $7.6 \%$ more than in alkylation under conditions calculated for the maximum yield of bitumoids, and $36.0 \%$ more than in sequential extraction according to the Grefe method.

The samples under study are complex multicomponent mixtures of substances of a predominantly aliphatic nature, aromatic substances are present in small quantities. The proportion of saponifiable substances, depending on the processing method, varies as follows: successive extraction according to Grefe $<$ O-alkylation $<\mathrm{O}$-alkylation under 
ultrasonic action. Aromatic substances during separation are concentrated in the saponifiable components. Comparison of the structural-group parameters of bitumoids obtained by alkylation and alkylation under ultrasonic action showed that in the latter the aromaticity index $\left(f_{\text {ar }}\right)$ doubles - this indicates an increase in the extractability of aromatic substances as a result of the intensification of the process by ultrasonic action.

More than 200 individual compounds have been identified in bitumen and their fractions, among which there are various biologically active substances.

The use of LC separation made it possible to increase the number of individual compounds identified in the GC-MS analysis. It should be noted that in the fractions eluted with toluene, there is a tendency to extract substances related to alcohols, terpenes and sterols, among which: Sugiol is a plant metabolite, has antiviral and antitumor activity; Ferruginol is a plant metabolite, has antitumor properties, etc. elution with ethanol made it possible to extract the numbers of fractions with a high relative content of Oleic acid - up to $75.8 \%$ (I CM2), which also has biological activity.

The identified biologically active substances can find their application in cosmetics, medicine, veterinary medicine, and agriculture. The method can be useful in the complex processing of brown coal.

\section{ACKNOWLEDGMENTS}

This work was supported by the Russian Foundation for Basic Research (grant № 19-3390079) and performed within the framework of a state contract at the Federal Research Center of Coal and Coal Chemistry, Siberian Branch, Russian Academy of Sciences (project № 121031500124-2).

\section{REFERENCES}

[1] Belkevich P.I., Golovanov N.G., Dolidovich E.F., (1989) Bitumen of peat and brown coal, Science and technology press, Minsk.

[2] Zherebtsov S.I., (2017) Alkylation with alcohols of solid fossil fuels of low degree of coalification. Doctoral thesis, Moscow chemical-technological university, Russia.

[3] Zherebtsov S.I., Moiseev A.I., (2008) Complex technologies and products of peat processing, brown and substandard coals of Kuzbass.
Mining Information and Analytical Bulletin, S7, 114-124.

[4] Shpakodraev K.M., Zherebtsov S.I., Smotryna O.V., Malyshenko N.V., Ismagilov Z.R., (2018) Structural-group and component composition of bitumen fractions of Tyulgan brown coal. Chemistry for Sustainable Development, Vol. 6, 707-716. DOI: 10.15372/KhUR20180617

[5] Zherebtsov I.P., Lobzin V.I., Zherebtsov S.I., Fedorova N.I., (1990) Investigation of the process of coal alkylation with methanol. Deposited manuscript, 1523-1590, 1-26.

[6] Shpakodraev K.M., Zherebtsov S.I., Malyshenko N.V., Ismagilov Z.R., (2020) Effect of the Oalkylation of brown coal with n-butanolon the yield and composition of bitumoids. Solid Fuel Chemistry, Vol. 4, 219-227. DOI: 10.3103/S0361521920040059

[7] Zherebtsov S.I., Moiseev A.I., (2009) Composition of the wax fraction of bitumoids of methylated brown coals. Solid Fuel Chemistry, Vol. 2, 12-21.

[8] Taits E.M., Andreeva I.A., (1984) Coal analysis and testing methods, Nedra press, Moscow.

[9] Shpakodraev K.M., Zherebtsov S.I., Smotrina O.V., et al., (2019) Study of the composition of the ethanol extract of brown coal for the isolation of biologically active substances. Chemistry for Sustainable Development, Vol. 4, 431-436. DOI: 10.15372/KhUR2019155

[10] Shpakodraev K.M., Zherebtsov S.I., Ismagilov Z.R., (2019) Study of the composition of nheptane and alcohol-benzene extract of brown coal for the isolation of biologically active substances. Chemistry for Sustainable Development, Vol. 6, 685-691. DOI: $\underline{10.15372 / K h U R 2019191}$

[11] Aivazov B.V., (1968) A practical guide to chromatography, Higher school press, Moscow.

[12] Nyquist R.A., (2001) Interpreting infrared, raman, and NMR spectra, V.1, Academic press, San Diego.

[13] Silverstein R.M., Webster F.X., Kiemle D.J., (2005) Spectrometric identification of organic compounds, 7th Ed., John Wiley \& Sons. inc., Hoboken.

[14] Pretsch E., Biihlmann P., Affolter C., (2000) Structure determination of organic compounds: 
tables of spectral data, 3rd Ed., Springer press, Berlin Heidelberg.

[15] Nakanishi K., (1965) Infrared spectra and structure of organic compounds, World press, Moscow.

[16] Kalabin G.A., Kanitskaya L.V., Kushnarev D.F., (2000) Quantitative NMR spectroscopy of natural organic raw materials and products of its processing, Chemistry press, Moscow.
[17] PubChem Chemical compounds and mixtures. USA.: National Center for Biotechnology Information. https://pubchem.ncbi.nlm.nih.gov (accessed: 07.08.2021).

[18] PubMed-Medical and biological publications. USA.: National Center for Biotechnology Information. https://pubmed.ncbi.nlm.nih.gov/ (accessed: 07.08.2021). 